\title{
Peasants' Income and Consumption Structure Contrasting: A Case Study on China's Sichuan Province
}

\author{
Tao Li \\ College of Economics Management, Sichuan Agricultural University \\ No.221, HuiMin Road, Wenjiang District, Chengdu 611130, China \\ E-mail: jnyytyw@qq.com \\ Dongmei Li (Corresponding author) \\ College of Economics Management, Sichuan Agricultural University \\ No.221, HuiMin Road, Wenjiang District, Chengdu 611130, China \\ E-mail: cndldm@163.com
}

Received: October 15, 2010

Accepted: November 12, 2010

doi:10.5539/ijef.v3n3p242

\begin{abstract}
This paper analyzed the income and consumption structure of the rural residents in China's Sichuan province from 2003 to 2009. Grey relative analysis model was used in this study; The research also predicted Sichuan peasants' income and various consumers spending from 2010 to 2012 with $G(1,1)$ model and contrasted the change of consumption structure characteristic fore-and-aft 2008. The result shows that the income change is relative to peasants' productive outlays, taxes and residence obviously in Sichuan. Their productive outlays are short, foodstuff and clothing consumption have a large proportion, and the characteristic of their consumption structure is still daily life type.
\end{abstract}

Keywords: Gray system, Peasants' income, Consumption structure, Sichuan province

\section{Introduction}

For a long time, "Urban-rural dual economic structure" has been a special social structure in China. It is an economic structure with the main characteristics of socialized production in the urban economy and the main characteristics of small-scale production in rural economy. China's urban-rural dual policy manufacture various inequality, the population is divided into two parts which named rural residents and urban residents. This classification makes the Chinese have different benefits from the birth, people born in urban have a better life starting from his birthday than in the countryside. These differences and inequalities cause more and more conflicts in recent years. For example, it makes the rural areas conflict with the urban areas, and leads to the famous "Three Agricultural Problems". More and more attention is focused on the "Three Agricultural Problems", especially the problem of peasants' income. In recent years, the gap of urban-rural income in China is widening which from 2.56/1 in 1978 to $3.33 / 1$ in 2009 . So it has great practical significance to research the factors that affecting the income and consumption of the peasants and increasing peasants' income.

Sichuan is a typical agriculture and services output province which located in the southwest of China, with 8984.7 million populations by the end of 2009. The 2286.3 million non-agricultural populations and 6698.4 million agricultural populations make up almost $25.45 \%$ and $74.55 \%$ respectively of the total population. On one hand, Chinese government began to pilot "China's Home Appliance Subsidy Program for Rural Areas Policy" firstly in Sichuan in December 2007 and it greatly droved rural consumption market development in Sichuan. On the other hand, as we all know, a terrible earthquake stroke WenChuan in Sichuan Province in 2008. A series of the country policies have been launched to improve people's production and living standards, which made a high stimulation for the rural consumption market in Sichuan. In these macro background, analyzing and forecasting the correlation size between income and consumption structure of rural residents in Sichuan fore-and-aft 2008 may has important theoretical and realistic significance.

Many projects about peasants' income and consumption have been studied by many scholars at home and abroad. Wu, Xuming, Perloff and Jeffrey M., \& Golan, Amosuy (2004) studied government policy effects on urban and rural income inequality by using the data from 1981 to1997, their results showed that government's policies have qualitative similar but quantitatively different effects on rural and urban areas; marginal income tax rates and the 
earned income tax credit play a more important role in equalizing income than do the other government programs in both areas; and income inequality measures for rural and urban areas have recently diverged. Albert Keidel (2009) divided China into seven regions reveals rural income and consumption divergence for both 1980-2005 and 2000-2005. He argued that more meaningful measures of regional disparities come from differences in regional poverty headcounts, and suggested that higher regional inequality and accompanying interregional migration indicated that inequality plays an important positive role in inducing economic actors voluntarily to move to more productive locations and activities as a mechanism for ensuring sustainable improvements in individual well-being. The study of Wei Xu, Yongyuan Yin and Suoquan Zhou (2007) revealed that socio-economic changes associated with the government-financed project are multifaceted and profound, and the land conversion project with continued financial support also contributes to the social transformations of traditional rural society in remote areas to a more mobile, less subsistence agriculture-based, and open society.

Researches on China's rural households' income and consumption structure have focused previously on two independent aspects: influence factors and countermeasures of peasants' income and peasant's consumption factor analysis. In the first aspect, experts concluded that the main factors influencing peasants' income were price scissors, education degree of peasants, government's countryside-supporting policy factors and rural social security system (Lin Li, 2006; Chunhua Wang, 2008; Jingjing Tong, 2007; Xiusheng Zhang \& Xiaoming Ma, 2009). Mingfeng He (2008) used the labor model analyzed the income of peasants in the rural areas of China. He found that a decision is made based on working ability and the information that a peasant gets. A multivariate evolutionary model about this problem is established and the numerical simulation shows that going to the city brings about a rise in the peasants' income. Zhaobo Liu (2009) established an error correction model (ECM) to analyze the factors influencing peasant's consumer behavior; the result concluded that the uncertainty, excess sensitivity and the life cycle characteristics of peasant's consumer behavior are the most important factors that affect peasant's consumer behavior. Jing Ji (2010) held that China's rural social security for peasants have a weak positive correlation with peasant's consumer spending in long-term and an inhibitory effect inhibition in short-term.

The foregoing studies provide a lot of essential information on the peasants' income and consumption. However, these researches and other existing works only focused on the independent aspects, there's no specific study has done on both peasants' income and consumption structure combining research. In addition, the earthquake increased many uncertain factors to peasants' income and consumption structure. Therefore the objective of this paper is to analyze, and find out the factors influencing their behaviors both on the macrocosmic and microcosmic level. We finally conclude the paper by offering a wider range of suggestions that not only helpful to government, but also to peasants and companies.

\section{Methodology and Materials}

According to international practice, the quantity of information is explained by color depth in cybernetics. White means sufficient and sure (known) information, while black is stand for lacking of information or uncertain (unknown), and part of certainty and parts of uncertainty is for the grey. Those systems who have known and unknown parameters are gray systems. Gray system contains known and unknown information (or the unascertained information). The primary mission of grey system theory is to propose the new ideas and methods of modeling for a gray system which is with information loss on the whole from the angle of cybernetics. It was published by Deng Julong in 1982.

\subsection{Grey relative analysis}

Gray Relative Analysis Method (GRAM) is a factor comparative analysis whose essence is to analyze the development and change trend. Its relative degree is measured by the difference value of curve. Through the analysis of correlation, we can find out the main factors which impact the development of key variables. The steps are as below.

Firstly, we select reference sequence $X_{0}(t)=\left\{x_{0}(1), x_{0}(2), \ldots \ldots, x_{0}(n)\right\} \quad, \quad$ and sequence $X_{i}(t)=\left\{x_{i}(1), x_{i}(2), \ldots \ldots, x_{i}(n)\right\}$ for comparison. Equation (1) is called the related coefficient between sequences $X_{0}\left(t^{\prime}\right)$ and $X_{i}\left(t^{\prime}\right)$.

$$
\xi_{i}(k)=\frac{\min _{i} \min _{k}\left|x_{0}(k)-x_{i}(k)\right|+\rho \max _{i} \max _{k}\left|x_{0}(k)-x_{i}(k)\right|}{\left|x_{0}(k)-x_{i}(k)\right|+\rho \max _{i} \max _{k}\left|x_{0}(k)-x_{i}(k)\right|}
$$

Where $\rho$ is resolution coefficient, generally being selected between 0 and 1 . where there is a bigger $\rho$, there is a 
higher resolution, vice versa.

So the average related coefficient of sequence $X_{0}\left(t^{\prime}\right)$ in each time is called the correlation which is subsequence $X_{i}\left(t^{\prime}\right)$ to compare sequence $X_{0}\left(t^{\prime}\right)$. Denoted by

$$
r_{i}=\frac{1}{N} \sum_{k=1}^{N} \xi_{i}(k)
$$

\subsection{Gray systematic predicting model}

Gray systematic predicting model (GM) established on the basis of the grey system theory. General GM model is a n-order and h-variable differential equation model, abbreviation for GM (n,h). GM $(1,1)$ is an one-order ordinary differential equation model $\hat{a}=\left(B^{T} B\right)^{-1} B^{T} Y_{N}$, supposing there is an original data column $X^{0}(k)=\left\{x^{0}(1), x^{0}(2), \ldots \ldots, x^{0}(n)\right\} \quad, \quad$ after $\quad$ an accumulated generating operation (AGO) we can get $X^{1}(k)=\left\{x^{0}(1), x^{1}(1)+x^{0}(2), \ldots \ldots . ., x^{1}(n-1)+x^{0}(n)\right\}$. Then $X^{1}$ can be established as the differential equation in standard form as follows:

$$
\frac{d X^{1}}{d t}+a X^{1}=u
$$

We mark Parameters listed with $\hat{a}$,

$$
\hat{a}=\left[\begin{array}{l}
a \\
u
\end{array}\right]
$$

Calculating $\hat{a}$ according to the least-square method, we can get the solution of the differential equation in standard form as follows:

$$
\hat{x}^{1}(k+1)=\left(x^{0}(1)-\frac{u}{a}\right) e^{-a k}+\frac{u}{a}
$$

Thus, a forecast model is established.

\subsection{Data}

According to the scope of statistics, peasants' consumer spending was constituted by 11 indexes, they are Expenditure for household business, Expenditure on purchasing productive fixed assets, Taxes, Food, Clothing, Residence, Household facilities \& articles and services, Medicine and medical services, Transportation and communications, Cultural, educational \& recreational articles services and Other commodities and services. The "Three Agricultural Problems" gradually being take seriously since 2000, considering the national policy's influence on rural income \& consumption level and its hysteretic characteristics, data for the study was based on time-series from 2003 to 2009(Table 1). 11 indices data were select from the Sichuan statistics yearbook (2004-2010). Firstly, this paper presents a quantitative analysis of the peasants' consumption structure with grey relational analysis method. Then to move forward a single step, we use grey systematic predicting method to establish the consumption expenditure predicting model, and predicate the consumption data from 2010 to 2012 (Table 2).

\section{Results and discussion}

\subsection{Model analysis and prediction}

Firstly, we will do the grey relative analysis, dimensionless process the data column, calculate correlation coefficient $\xi_{i}(k)$ and calculate the index relational according to formula. Results are listed in table 3.

Secondly, we predict the income and expenditure. In order to reflect the dynamic influence of peasants' income to consumption structure, we need to predict the income and expenditure data in Sichuan province according to the existing data. So establishing the foregoing sequence's gray systematic predicting model is indispensable, each sequence's GM $(1,1)$ models are as follows:

Annual income ( $\mathrm{Y}$ )

Family business expenses (a)

Expenditure on purchasing productive fixed assets (b)

Taxes (c)

Food (d)

$$
\begin{gathered}
\mathrm{Y}^{1}(k+1)=32935.22 e^{0.1073 k}-29679.45 \\
\mathrm{a}^{1}(k+1)=12504.59 e^{0.0818 k}-11644.30 \\
b^{1}(k+1)=127.66 e^{0.2766 k}-74.16 \\
c^{1}(k+1)=223.21 e^{-0.0812 k}+270.01 \\
\mathrm{~d}^{1}(k+1)=11168.49 e^{0.0932 k}-10226.79
\end{gathered}
$$


Clothing (e)

Residence (f)

Household facilities \& articles and services $(\mathrm{g})$

Medicine and medical services (h)

Transportation and communications (i)

Cultural, Educational and recreational articles services $(j)$

Other commodities and services

$$
\begin{aligned}
& e^{1}(k+1)=654.73 e^{0.1408 k}-568.79 \\
& f^{1}(k+1)=163.02 e^{0.4162 k}+61.78 \\
& g^{1}(k+1)=354.74 e^{0.1987 k}-289.89 \\
& h^{1}(k+1)=715.70 e^{0.1514 k}-624.34 \\
& i^{1}(k+1)=787.82 e^{0.1643 k}-682.63 \\
& j^{1}(k+1)=7584.65 e^{-0.0284 k}+7786.92 \\
& k^{1}(k+1)=277.65 e^{0.1141 k}-246.73
\end{aligned}
$$

Through Residual Test and Posterior-variance-test, the model is the accordance with the forecast rule, and the validity, feasibility and suitability, can be used to predict. Predicting result is listed in table 2 . Thus we obtain the peasants' income and consumer spending of Sichuan province between 2003 and 2012. To reveal the data's characteristics in different stages scientifically, we did a stage division before comparative analyzing. Considering the research purpose and the influence of macro background, these data were divided into two phases: 2003-2007 and 2008-2012. Repeating the grey relational analysis, we can get associated as grey relational analysis results (Table 4).

\subsection{The results and analysis}

From table 4, we can see clearly that the grey relational grade of family business expenses and expenditure on purchasing productive fixed assets presents downward trend. That is to say, with the increase of peasants' income, their investment on agricultural producing and managing relative decrease. The reasons are as follows: Sichuan is a big labor output province whose agriculture is in an inferiority status. Especially after the earthquake, the rural family need self-raised funds of reconstruction, it make most traditional young male labors go out to work for money. The old men left for farming only farm the land of their own, even give their land to others for free or let them fallow. Their land production and management are only to ensure the basic life, and their main family income source is outdoor-workers wages.

The relational sequence of peasants' income and residence consumption drastically drop from 5th to 11 th, the possible reason is that the central government offered lots of housing construction material support after the earthquake to safeguard national people's livelihood. And house is real estate whose service life is longer than the average consumer goods. Along with the increase of peasants' income and optimization of consumption structure, peasants request more comfortable living environment and their consumption focus are transform from quantity to quality.

The relational sequence of peasants' income and household facilities \& articles \& services make a clear ascendant trend, from 0.734 to 0.822 , but its sequence remains unchanged. It clearly state that "China's Home Appliance Subsidy Program for Rural Areas" policy played an important role in pulling the rural consumption, improving rural people's livelihood, putting energy conservation and emission reduction into effect and perfecting rural production and circulation system. But its growth has been weakly impact by the growth of income, stating clearly there are still many problems in the process in the implementation of the policy.

Generally speaking, the consumption of peasants in Sichuan is still shows basic life consumption characteristics, food and clothes consumption represent a significant proportion (Sorting by former); medicine \& medical services, transportation and communications and educational and recreational articles services turn up certain increase, they will be the consumption hotspot in following years. The main reason of the phenomenon is peasants living standards improved significantly in recent years (The rise of taxes and income' grey correlation degree sorting, from the last to 8th powerful explains it), and peasants' safety awareness to the product quality and safety also improved. Education expenses increased, demonstrating peasants pay more and more attention to education, not only on their children but also on quality of themselves. Their demand is gradually changing from the material consumption demand to the mental. Other commodities and services spending rise to second. It is a sign that a series of changes will occur on peasants' consumer content, consumption pattern and consumption concept with the increase of peasants' income.

\section{Discussion and Conclusions}

This paper developed a theoretical framework to analyze the change of income and consumption structure fore-and-aft Earthquake in Sichuan China. The Grey relative analysis and gray systematic predicting model were used to analyze the peasants' consumption structure and its influencing factors. The results indicate that the contemporary rural land policies adopted in China actually placed agriculture in a secondary position in the 
urban-rural dichotomous economy. The correlation grades of Sichuan peasants' productive outlays, taxes and residence relative to income change obviously. Concretely speaking, their productive outlays is short, foodstuff and clothing consumption take a big proportion, and the characteristic of their consumption structure is still daily life type.

After the earthquake, the mentality of rural residents had undergone some changes. They pay more attention to their health, the quality of life, culture \& entertainment and education expenditures. Notable changes have taken place in peasants' income and consumption structure correlative, and a series of problems can be deduced from these changes, such as the insufficient agricultural production force and unreasonable consumption structure. But in general, China's macroeconomic environment still affect the rural consumption market in Sichuan province, the basic living cost has played a large proportion of the peasants' consumption. On the other hand, Peasants' income growth is slow, the difference in the urban-rural income gap has widened, with 9,640 Yuan, or around \$1,400 U.S. dollars, forming the biggest average per capita gap since 1978. Under such circumstances, the government should meet with tough challenges such as who will take up farming in the future and how to promote the urbanization of peasants.

Therefore, we should focus on that how to make the post-disaster reconstruction of rural economy more scientific and formulate measures to transform Chinese peasants' traditional consumption idea. We argue that the government should continue to unveil fresh preferential policies which encourage peasants to consume, and adjust the rural consumption market product structure in order to adapt to the pluralistic demand tendency village people. Meanwhile, China's rural social security is a neglected problem, if this problem cannot be solved; peasants' consumption is difficult to ascend. These are worthy to be further researched topics.

As this paper focused only on Sichuan provide, it is unable to speak volumes for explaining the general situation in China. This is thus a major limitation of this work. Nevertheless, as the findings and suggestion provide useful information, it will help provide better understanding of the general situation of the country.

\section{References}

Albert Keidel. (2009). Chinese Regional inequalities in Income and Well-being: Review of Income and Wealth ,Series 55, Special Issue 1.

CHEN, xianyin. (2004). Impact of Education on Sustainable Income Growth of Chinese Farmers: Journal of Agrotechnical Economics, 6 , 52-56

DENG Julong. (1985). Gray Controlling System. (1rd ed.).Wuhan: Huazhong Polytechnic College Press (in Chinese).

HE, Mingfeng, Chuan Li, Tong Tong and Ma, Tianliang. (2008). A Model of Peasant Labor in China. Physical A: Statistical Mechanics and its Applications, 1, 1621-1627

HU, Xueping. (2003). Optimizes Consumption Environment of Rural and Enlarges Farmers' Consumer Demand: ISSUES IN AGRICULTURAL ECONOMY, 6, 47-50.

HE, Xianping, CHEN, suo. (2009). The Substantial Evidence Study for the Implementing Effect of Chinese Agriculture Policy: Statistics and Decision, 6, 88-89

JI, Jing. (2010). The Influence of the Social Security on the Consumption Expenditure of Rural Residents: Human Resource Management, 4, 260-261

LIU, Zhaobo. (2006). The Study on Present Farmers' Consumption Behavior: FINANCE \& ECONOMICS, 6, 75-83.

WU, Xuming, Perloff, Jeffrey M., \& Golan, Amos. (2004). Government Policy Effects on Urban and

Rural Income Inequality: Institute for Research on Labor and Employment. Retrieved from: http://escholarship.org/uc/item/1111d59t.

XU, WYin, YZhou S. (2007). Social and Economic Impacts of Carbon Sequestration and Land Use Change on Peasant Households in Rural China: A Case Study of Liping, Guizhou Province: Journal of Environmental Management, 3, 736-745.

ZHANG, Xiusheng, MA xiaoming. (2009). Analysis on the Interaction Between Rural Social Security System and the Increase of Farmers' Income: Wuhan University Journal(Philosophy \& Social Sciences) , 2 , 255-260. 
Table 1. 2003-2009 Sichuan rural income and consumption data

\begin{tabular}{|lccccccc|}
\hline Article of Consumption & 2003 & 2004 & 2005 & 2006 & 2007 & 2008 & 2009 \\
\hline Annual income & 3255.78 & 3805.02 & 4158.19 & 4342.82 & 5096.98 & 5903.28 & 6238.49 \\
Expenditure for household business & 860.29 & 1073.85 & 1188.2 & 1167.93 & 1368.54 & 1578.71 & 1555.07 \\
Expenditure on purchasing productive fixed assets & 53.5 & 47.08 & 67.53 & 76.8 & 87.2 & 107.77 & 186.18 \\
Taxes & 46.86 & 26.3 & 4.89 & 12.04 & 16.24 & 13.11 & 13.75 \\
Food & 941.7 & 1118.34 & 1244.36 & 1216.19 & 1435.52 & 1627.58 & 1740.59 \\
Clothing & 85.94 & 92.87 & 115.32 & 133.3 & 156.65 & 174.59 & 197.06 \\
Residence & 224.8 & 234.31 & 234.05 & 328.58 & 366.45 & 469.73 & 1138.72 \\
Household facilities \& articles and services & 64.85 & 79.15 & 102.13 & 114.13 & 142.64 & 163.99 & 219.63 \\
Medicine and medical services & 91.36 & 117.4 & 144.45 & 160.31 & 174.75 & 209.22 & 258.13 \\
Transportation and communications & 105.19 & 127.6 & 171.5 & 203.63 & 241.49 & 256.08 & 324.05 \\
Transportation and communications & 202.27 & 209.68 & 225.16 & 196.64 & 177.19 & 173.26 & 206.67 \\
Other commodities and services & 30.92 & 31.54 & 36.18 & 42.26 & 52.56 & 53.49 & 56.55 \\
\hline
\end{tabular}

Notes: Unit is RMB Yuan.

Source: Sichuan statistics yearbook (2004-2010).

Table 2. Predicted data of Sichuan peasants' income and various consumers spending from 2010 to 2012

\begin{tabular}{|c|c|c|c|c|c|c|c|c|c|c|c|c|}
\hline Year & Y & $\mathrm{a}$ & b & $\mathrm{c}$ & d & $\mathrm{e}$ & $\mathrm{f}$ & g & $\mathrm{h}$ & $\mathrm{i}$ & $\mathrm{j}$ & $\mathrm{k}$ \\
\hline 2010 & 7022.87 & 1742.24 & 213.75 & 10.69 & 1909.17 & 230.46 & 1022.12 & 256.89 & 290.07 & 376.77 & 179.12 & 66.49 \\
\hline 2011 & 7812.84 & 1890.81 & 281.85 & 9.86 & 2095.71 & 265.31 & 1549.7 & 313.36 & 337.47 & 444.03 & 174.1 & 74.53 \\
\hline 2012 & 8691.66 & 2052.04 & 371.64 & 9.09 & 2300.47 & 305.43 & 2349.59 & 382.24 & 392.63 & 523.29 & 169.23 & 83.53 \\
\hline
\end{tabular}

Notes: $Y$ represents annual income, a represents family business expenses, $b$ represents expenditure on purchasing productive fixed assets, and so on.

Unit is RMB Yuan.

Source: The data comes from forecasting model operation.

Table 3. Grey relational grades of Sichuan peasants' various consumers spending to income from 2003 to 2009

\begin{tabular}{|cccccccccccc|}
\hline Article of Consumption & $\mathrm{a}$ & $\mathrm{b}$ & $\mathrm{c}$ & $\mathrm{d}$ & $\mathrm{e}$ & $\mathrm{f}$ & $\mathrm{g}$ & $\mathrm{h}$ & $\mathrm{i}$ & $\mathrm{j}$ & $\mathrm{k}$ \\
\hline Correlation value & 0.969 & 0.875 & 0.636 & 0.974 & 0.854 & 0.838 & 0.788 & 0.826 & 0.784 & 0.800 & 0.950 \\
\hline
\end{tabular}

Notes: "a" represents family business expenses, "b" represents expenditure on purchasing productive fixed assets, "c" represents taxes, and so on.

Table 4. Grey relational grades of Sichuan peasants' various consumers spending relative to income and their ranking

\begin{tabular}{|cccccccccccc|}
\hline Article of Consumption & $\mathrm{a}$ & $\mathrm{b}$ & $\mathrm{c}$ & $\mathrm{d}$ & $\mathrm{e}$ & $\mathrm{f}$ & $\mathrm{g}$ & $\mathrm{h}$ & $\mathrm{i}$ & $\mathrm{j}$ & $\mathrm{k}$ \\
\hline 2003-2007 & 0.932 & 0.883 & 0.508 & 0.955 & 0.844 & 0.856 & 0.734 & 0.747 & 0.705 & 0.741 & 0.885 \\
Ranking & 2 & 4 & 11 & 1 & 6 & 5 & 9 & 7 & 10 & 8 & 3 \\
$2008-2012$ & 0.952 & 0.693 & 0.854 & 0.986 & 0.931 & 0.602 & 0.822 & 0.896 & 0.865 & 0.895 & 0.977 \\
Ranking & 3 & 10 & 8 & 1 & 4 & 11 & 9 & 5 & 7 & 6 & 2 \\
\hline
\end{tabular}

Notes: "a" represents family business expenses, "b" represents expenditure on purchasing productive fixed assets, "c" represents taxes, and so on. 